Images in. ..

\title{
Striking electrical and mechanical alternans associated with cardiac tamponade
}

\author{
Mohamed Jeilan, ${ }^{1}$ Abubakar Habib, ${ }^{2}$ Helen Colver ${ }^{3}$ Suman Kundu, ${ }^{1}$ Noor Mohammed, ${ }^{4}$ lan Loke ${ }^{5}$
}

${ }^{1}$ Glenfield Hospital, Leicester, UK

${ }^{2}$ Warwick University, Leicester, UK

${ }^{3}$ Department of Medicine, Leicester Royal Infirmary, Leicester, UK

${ }^{4}$ Department of Cardiology, Leicester Royal Infirmary, Leicester, UK

${ }^{5}$ University of Hospitals of Leicester NHS Trust, Leicester, UK

Correspondence to Dr Mohamed Jeilan, jokumali@hotmail.com

\section{DESCRIPTION}

A 39-year-old woman with several weeks' history of malaise and shortness of breath was referred because of acute deterioration. Examination revealed a regular tachycardia of $110 \mathrm{bpm}$, evidence of pulsus alternans and a blood pressure of $120 / 74$, but was otherwise unremarkable. A routine admission 12-lead ECG (figure 1) demonstrated low voltage ORS alternans. As a result of this finding, an urgent transthoracic echocardiogram (TTE) was arranged.

TTE (figure 2, video files) confirmed a large, circumferential pericardial effusion with signs of tamponade. Soon after, the patients condition declined and blood pressure dropped to $95 / 65$ with pulsus paradoxus $>10 \mathrm{~mm} \mathrm{Hg}$ detected manually. Pericardiocentesis under echo-guidance was performed promptly and $900 \mathrm{ml}$ of serosanguineous fluid was removed with immediate resolution in symptoms and an improvement in blood pressure to $139 / 87$. Repeat ECG (figure 3) after drainage revealed resolution of electrical alternans.

Pericardial effusion should be considered likely when electrical alternans is seen in the presence of pulsus alternans, particularly when there is no evidence of explanatory arrhythmia on ECG. When present in this context, ORS alternans typically signifies a large, haemodynamically significant, effusion and urgent imaging to confirm the diagnosis and to guide treatment is important. In effusionrelated ORS alternans, the heart swings once every second beat (2:1 swinging). This pendular cardiac motion is visible on echocardiography. True 2:1 ORS alternans occurs within a limited range of heart rates defined mathematically by the relative durations of diastole and systole.

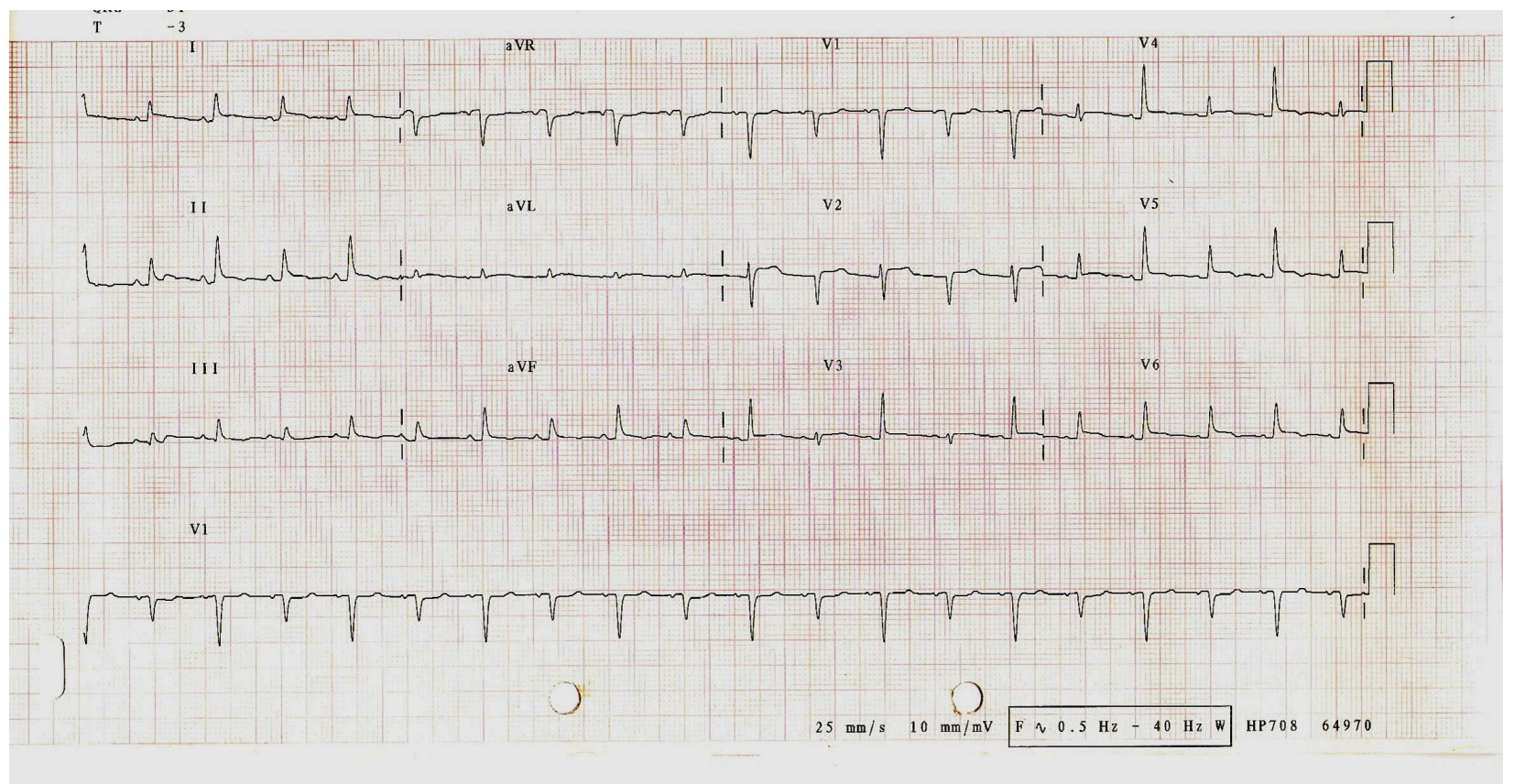

Figure 1 12-Lead ECG demonstrating QRS alternans best seen in leads V3 and V4. 


\section{BMJ Case Reports}
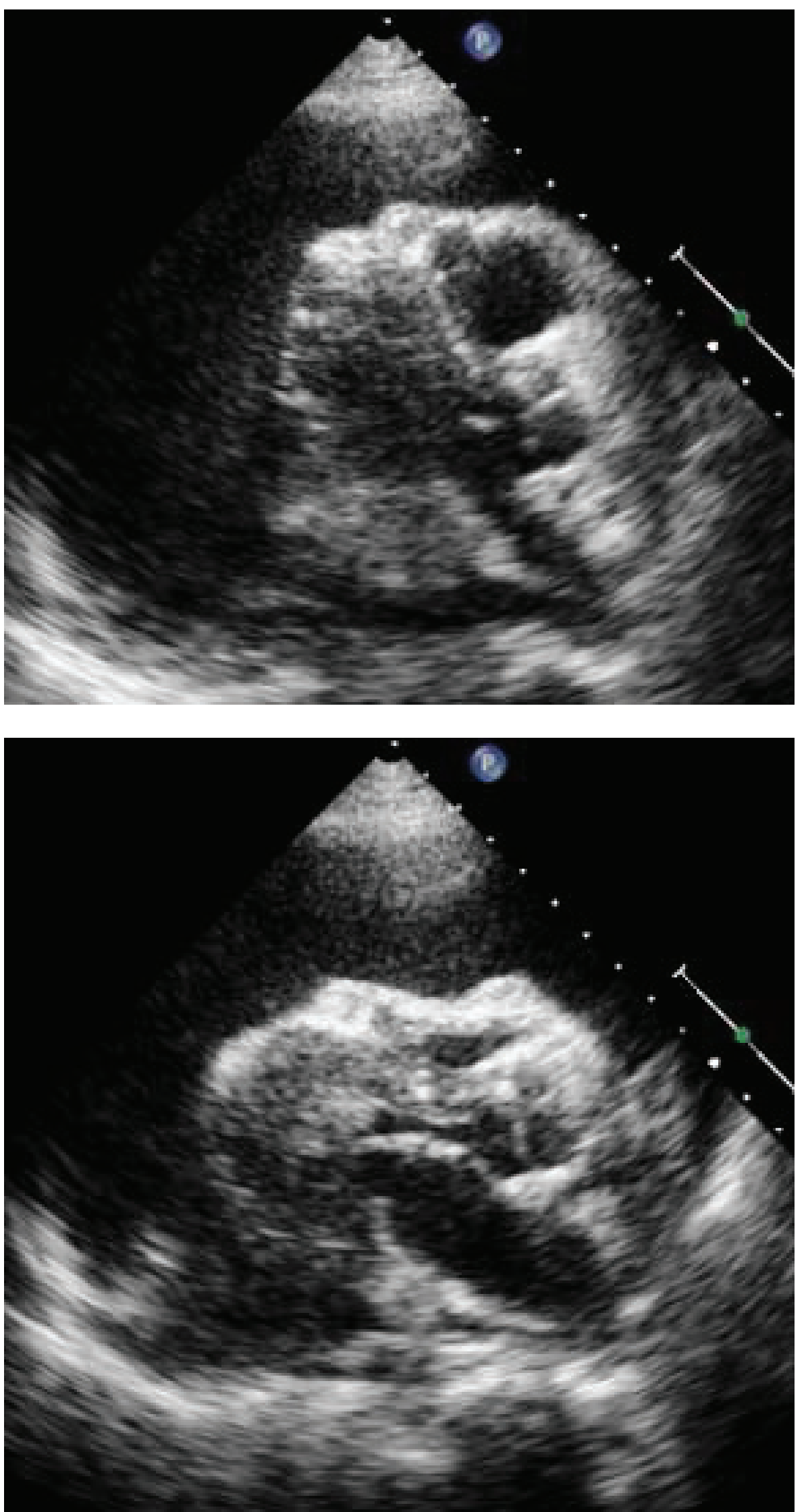

Figure 2 Parasternal views of the heart in mid-diastole. The position of the heart alternates within two consecutive heart beats, with the septum swinging along an antero-posterior axis. Anterior displacement of the septal wall results in the larger QRS amplitude (corresponding with chest leads V3 and V4 on ECG), whereas posterior displacement of the septum produces the smaller amplitude (almost negative) QRS. 


\section{BMJ Case Reports}

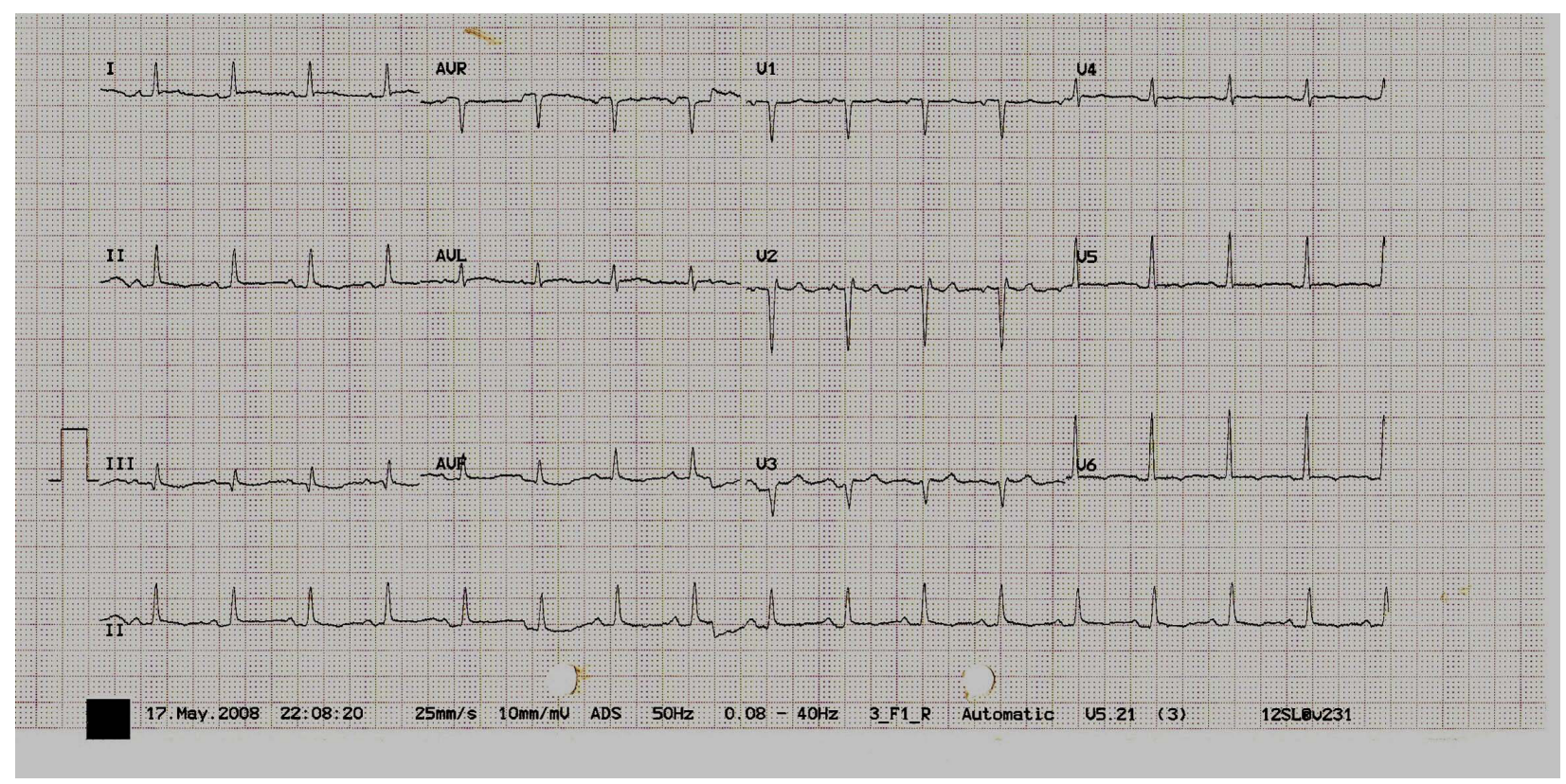

Figure 3 12-Lead ECG performed following drainage demonstrating resolution of ORS alternans.

Competing interests None.

Patient consent Obtained.

This pdf has been created automatically from the final edited text and images.

Copyright 2010 BMJ Publishing Group. All rights reserved. For permission to reuse any of this content visit http://group.bmj.com/group/rights-licensing/permissions. BMJ Case Report Fellows may re-use this article for personal use and teaching without any further permission.

Please cite this article as follows (you will need to access the article online to obtain the date of publication).

Jeilan M, Habib A, Colver H, Kundu S, Mohammed N, Loke I. Striking electrical and mechanical alternans associated with cardiac tamponade. BMJ Case Reports 2010;10.1136/bcr.06.2008.0100, date of publication

Become a Fellow of BMJ Case Reports today and you can:

- Submit as many cases as you like

- Enjoy fast sympathetic peer review and rapid publication of accepted articles

- Access all the published articles

Re-use any of the published material for personal use and teaching without further permission

For information on Institutional Fellowships contact consortiasales@bmjgroup.com

Visit casereports.bmj.com for more articles like this and to become a Fellow 